\title{
The effect of natural environments upon agitation and aggression in late stage dementia patients
}

\author{
Ann L. Whall, $\mathrm{PhD}, \mathrm{RN}$ \\ Margaret E. Black, PhD, RN \\ Carla J. Groh, $\mathrm{PhD}, \mathrm{RN}$ \\ Dawn J. Yankou, PhD, RN \\ Barbara J. Kupferschmid, MSN, RN \\ Norman L. Foster, MD
}

\begin{abstract}
Agitated aggressive behavior in late stage dementia occurs in 30 to 50 percent of patients. This behavior often results in the use of chemical and physical restraints (which have a high degree of untoward side effects) and caregiver burnout. Interventions for agitated aggressive behavior are needed that do not have these side effects, which are readily available in nursing homes and are effective and acceptable to caregivers. Environmental psychologists have proposed that natural elements within the environment decrease agitation in the nondemented as well as the demented. Since the shower bath is often a time of great agitation in dementia patients, natural elements were used to modify care during the shower bath $(n=31)$. There was a significant decrease in mean difference scores from baseline to treatments one and two, with the treatment group demonstrating an overall decline in agitated aggressive behavior. Additional randomized trials of the effects of natural environments upon agitation and aggression in dementia are needed.
\end{abstract}

Ann L. Whall, PhD, RN, School of Nursing, University of Michigan, Ann Arbor, Michigan.

Margaret E. Black, PhD, RN, School of Nursing, McMaster University, Hamilton, Ontario, Canada.

Carla J. Groh, PhD, RN, College of Health Professions, University of Detroit Mercy, Detroit, Michigan.

Dawn J. Yankou, PhD, RN, Faculty of Health Sciences, University of Western Ontario, London, Ontario, Canada.

Barbara J. Kupferschmid, MSN, RN, School of Nursing, University of Michigan, Ann Arbor, Michigan.

Norman L. Foster, MD, School of Medicine, University of Michigan, Ann Arbor, Michigan.

\section{Introduction}

This study examined the effect of natural environments upon agitated and aggressive behavior in late stage dementia patients. Agitated aggressive behavior in late stage dementia is one of the most difficult aspects of care. ${ }^{1-3}$ According to the National Nursing Homes Survey, the majority (30-50 percent) of patients with Alzheimer's disease exhibit agitated/aggressive behavior during late stage dementia. ${ }^{4}$

Clinicians in nursing homes often use two methods to address agitated/aggressive behavior-psychotropic medications and physical restraints. ${ }^{5}$ These interventions, however, are often problematic in themselves. ${ }^{6-7}$ Pharmacologic interventions, for example, can cause permanent damage such as tardive dyskinesia and the neuroleptic malignant syndrome. Likewise, the use of physical restraints reduces quality of life and has led to falls and other injuries. In 1987, the Nursing Home Reform Act placed restrictions on both physical and chemical restraints for nursing home residents, making the search for other treatments for agitation more critical. ${ }^{8}$

This study was based on findings from environmental psychology, which identifies that modifications in the environment to include multiple nature experiences may have a calming and restorative effect upon persons with compromised cognitive abilities. ${ }^{9-10}$ Kaplan, for example, posits that remembrance of things past (e.g., animals, plants) which are laid down in early memory may result in clarity and thus pleasure for the demented. Whether these findings are related to those on implicit memory in Alzheimer's disease is as yet unclear. ${ }^{11}$ However, a positive prior response of 
Alzheimer's disease patients to plants and animals may account for a portion of the increased affect during these natural experiences.

This study used the natural elements of bird songs, bird pictures, the sound of babbling brooks, and food to increase the demented person's experience of natural elements during nursing care. It was posited that this experience would result in a decrease in agitation and aggression during care routines such as the shower bath. (The shower bath has consistently been associated with aggressive behavior in the demented). ${ }^{12}$ For those institutionalized in late-stage dementia, nursing homes are not remembered experiences as evidenced by repeated requests to go home or to remove the strangers from their home. Natural elements, however, such as the sounds of birds and accompanying pictures, appear to be remembered $^{13}$ and may hearken back to a safer more pleasant time in their lives. Natural elements thus may draw upon some portion or type of remaining memory in late stage Alzheimer's disease. In this study, the response of late stage dementia patients to natural elements during a care procedure was examined.

Understanding of the extent to which patients with Alzheimer's disease and other permanent dementias might respond positively to an environment of natural elements was unclear, however, as nursing home patients are rarely exposed to these types of elements. This pilot effort sought to determine if an increase in natural elements during a nursing care procedure (shower-bath) would decrease the frequency of agitation and aggressive behavior in these patients.

\section{Study subjects}

Following approval of the Human Subjects Review Committee, patients' relatives were sent letters requesting participation in the study. Eleven relatives out of 79 refused participation (14 percent) after the study was described; relatives refusing participation were supportive of the study, but most felt their relatives "had been through enough." Upon written approval of the relative, patients were explained the study in simple terms. Three out of 35 patients refused assent (.08 percent) after relative's approval was granted and although it was not certain that their "no, no, no" was related to the study, their seeming decision was respected.

Of the thirty-one patients who constituted the nonprobability sample, 15 were in the natural experience group and 16 in the usual care group. All but four patients were women, and all were diagnosed with latestage Alzheimer's disease (AD) or AD with multiinfarct dementia. After permission was given, subject eligibility was determined using the following criteria:
- All had a recently reconfirmed diagnoses of $\mathrm{AD}$ or a mixture of $\mathrm{AD}$ with multi-infarct dementia;

- Subject symptoms were congruent with that of AD or multi infarct dementia as found in the Diagnostic and Statistical Manual of the American Psychiatric Association (4th edition);

- Agitated aggressive behavior such as hitting, kicking and biting was displayed by the subjects during the shower-bath at least half the time;

- Subjects had scores of five or less on the Mini Mental Status Exam;

- None of the subjects had an acute health condition; and

- During the consecutive three shower-baths that were observed the facility agreed to maintain any psychotropic drugs at a constant level.

In that aggressive behavior continued in these patients, the psychotropic drugs were not having an observable effect upon this behavior. All patients meeting the study and human subjects criteria were accepted into the study.

The setting was five nursing homes from among a group of 17 from within one nursing home corporation; all the homes were located in a similar working-class area of a large US Midwestern city and all care and training procedures were uniform throughout the 17 homes. The most frequent form of payment for care was Medicaid. In addition, the nursing home corporation had a stable staff with several nurse aides who had been employed for over one year. This latter feature (in the view of the nursing home administration) was related to aide agreement to cooperate with projects such as research. Two out of the five homes served as treatment homes and the three others as comparison homes. All five homes had similar age and racial characteristics of aides and patients.

Nurse aides at each home were selected from a pool of those who met the aide criteria: employment for over one year within the homes, willingness to give three consecutive morning shower-baths to the same patients, and willingness to be observed along with the patients during their showering of these patients. The majority of the nurse aides who had the study explained to them agreed to participate (15 out of 20), and those who refused most often stated they would like to participate, but had scheduling or other similar problems. Nurse aides in both the treatment and comparison homes had received the routine training of the nursing home corporation in shower care; this training conformed to that required by federal and state licensing agencies.

For the treatment group, the aides gave the usual care 
at one baseline shower-bath before they were trained in the natural treatment. The treatment group aides $(n=10)$ were then taught in three sessions (a total of approximately one hour) to give the shower while using natural elements. After the baseline, at two subsequent baths one week apart, treatment group aides gave the natural treatment to these patients during the shower bath. The aides were held constant (same aide gave bath to same patient) across both groups. The number of patients each aide worked with ranged from one to seven. All aides were blind to study hypotheses.

Patient behavior during all baths was rated by research assistants expert in rating agitation and aggression using the Cohen-Mansfield Agitation Inventory (CMAI); the CMAI has a subset of aggressive questions within the 29-item instrument. The CMAI was originally constructed from clinical observations of demented patients by nurses who completed the CMAI from retrospective recall of a care event. ${ }^{13,14}$ In this initial format an inter-rater reliability of .88 was reported. A later study using the retrospective format CMAI with 408 nursing home residents confirmed inter-rater reliabilities of $.92, .92, .88$, among three sets of raters. ${ }^{13}$

The Cohen-Mansfield Agitation Inventory was modified by Whall ${ }^{15}$ for usage as a direct observational tool to be used during distinct care procedures such as the shower-bath. The items remained constant, only the format was changed. The interrater reliability of this new form ranged from .72 to .81 in the three observations. The agreement of this modified form was .80 with the Ward Behavior Inventory, an older, more established instrument. The modified form of the CMAI was used in this study.

\section{Treatment}

The comparison group received the usual care during the three observations with expert RAs rating patient behavior using the CMAI. The treatment group after the baseline, however, were bathed in a shower room that featured recorded songs of birds, sounds of babbling brooks, and the sounds of other small animals such as ducks, kittens, chickens. In addition, large bright pictures (capable of being seen by persons with presbyopia, but not wearing glasses) were coordinated with the audio tapes. A third element in the environment that continued the natural theme was the offering of foods such as banana pudding and/or soda. Preinterviews of the nursing home dietician and staff were used to identify patient food preferences compatible with patient dietary restrictions.

Patients in both groups were given the usual shower at baseline or the first occasion. Their behavior was recorded by the expert RAs using the CMAI. The aides, who were assigned to use the natural treatment on the second and third occasions, were trained to ask the patient, "Do you hear a bird? What kind of bird is it?" The aide would then refer to a picture of the bird, and say, for example, "I think it's a duck. Can you see the duck?" If the patient responded to the natural element, the discussion continued of that particular natural element until patient attention appeared to wane. At that point, another picture or food would be offered. "Here is some banana pudding," the aide would say and a small amount of pudding was placed upon the lip of the patient as the discussion of the pudding ensued. If the patient enjoyed the food, more would be offered and discussion of the natural sights and sounds also continued. The treatment aide was trained not to discuss other topics other than the natural sights, sounds or food.

In this way, care was focused upon natural elements within the environment (e.g., bird sounds, pictures, and foods) and not upon the shower procedure itself or upon the agitated aggressive behavior of the patient. Besides the quantification of agitated, aggressive behavior, data were also collected for vignette case studies concerning the affect of patients.

\section{Results}

The mean length of the shower bath in both groups was seven to 10 minutes. In order to determine whether the natural element approach decreased agitated and aggressive behavior in the treatment group, three scores were compared on the CMAI, at the baseline to time one (T1), at baseline to time two (T2), and from T1 to T2. Ttests for independent samples conducted used mean difference scores, compared treatment and control groups at the three time periods. The results support a significant decline in agitated behavior from baseline to $\mathrm{T} 1$ and T2; agitation decreased significantly in the treatment group as compared to the comparison group. There was not a significant difference between $\mathrm{T} 1$ and $\mathrm{T} 2$ as treatment continued (see table 1).

\section{Table 1. T-tests of mean difference scores on agitation between treatment and com- parison group}

Mean baseline to T1, $-5.08 ; \mathrm{SD} 2.12 ; \mathrm{t}=2.40, \mathrm{p}<.02$

Mean baseline to T2, $-6.73 ;$ SD 2.15; $t=3.13, p<.004$

Mean T1 to T2, $-1.98 ;$ SD 1.55; $\mathrm{t}=-1.27, \mathrm{p}<.21$ 
The seven items on the CMAI that addressed specific aggression such as hitting also were examined separately from the total agitation score. The mean difference scores on these items alone was baseline to $\mathrm{T} 1, \mathrm{t}=-.64, \mathrm{p}=.53$; baseline to $\mathrm{T} 2, \mathrm{t}=-1.47, \mathrm{p}<.19$. Thus physical aggression as a separate entity from agitation decreased over time in the treatment group, but the decrease did not reach significance. It is thought that the aggression items on the CMAI are too few in number to completely capture aggressive behavior as separate from overall agitation; in future studies the Ryden Aggression Scale ${ }^{16}$ will be used along with the CMAI. ${ }^{15}$

In order to assess whether the two research assistants' observations were confounded by a systematic bias, a covariate analysis of the RAs' ratings were also made. It was found that the identity of the RA doing the rating did not contribute significantly to the change in scores, thus indicating that there were no systematic difference between the RA raters.

\section{Case study reports}

Case studies describe the affective response of patients to the natural environments. (Characteristics have been changed to protect identities).

Martha was an 80-year-old late-stage $\mathrm{AD}$ patient whose MMSE was less than five on multiple occasions. She consistently demonstrated agitated and aggressive behavior during the shower-bath. The caregivers using natural elements met Martha at the bedside and without discussing the shower asked her if she would like banana pudding. She accepted the offer and she was told more food was available down the hall. At the shower room entrance, Martha began hanging onto the door frame to stop entry. We began the bird sounds and pictures and Martha began looking around and allowed her wheelchair to enter the shower room. Martha accepted more food at this point and when she was asked questions about the bird songs and pictures, she tried to speak. Martha allowed the entire shower to be completed without her usual screaming/hitting/biting. The shower aide found her behavior very different from that usually displayed. During the first treatment Martha's affect went from angry to neutral, and then she attempted smiling. At the last treatment, Martha tried to speak the bird names and smiled intermittently.

Lucy was in her late $80 \mathrm{~s}$, also diagnosed with Alzheimer's disease. She used language infrequently and displayed agitation and aggression (hitting) when her clothing was removed for bathing purposes. Her Mini Mental Status Exam was also less than five on all occasions. The bird calls and songs were played as she entered the shower room and she began to be undressed.
Lucy tried to speak when she was asked, "Do you hear a bird?" During the remainder of the shower, she displayed no agitation or aggression. During the second natural treatment, Lucy looked around and smiled as she was wheeled into the shower room and for the first time in many days she tried to speak. She smiled and said the word bird and later duck when she heard the bird sounds and saw the pictures. When an aide asked her if she had ever cooked a duck, she said fat. The aides enjoyed her comment as they later shared that when one cooks a duck, much fat is produced. Lucy did not display agitated aggressive behavior throughout the second shower and her affect noticeably improved.

\section{Discussion}

The use of natural elements within the environment, such as bird calls and pictures in conjunction with other natural elements such as food, was associated with decreased patient agitation and aggression and a more positive affective response. Use of natural elements during the shower bath took an average two minutes longer than usual care, primarily because of the food that was offered. However, this treatment does not appear costly as such resources are readily available in most nursing homes. In addition the aides in the treatment group enjoyed the natural experience and their affect also became more positive in the opinion of the study RAs.

Limitations concern the non-randomized nature of the study and resultant generalizability issues. Whether natural elements will make a significant difference in agitation, aggression, and patient affect in randomized trials is yet to be addressed, although case study results are supportive of study findings. The use of natural environments to combat agitation and aggression in late stage dementia patients during care routines is viewed, however, as a promising approach and one that warrants further controlled investigations.

\section{Acknowledgment}

Funding for this project was provided by the National Institute of Nursing Research, F33 NR06911-01; The University of Michigan Office of Vice President for Research; and the National Institutes of Health, P50-AG0871 (MADRC).

\section{References}

1. Whall A, Gillis G, Yankou D, Booth D, Beel-Bates C: Disruptive behavior in elderly nursing home residents. Journal of Gerontological Nursing. 1992; 18 (10): 13-17.

2. Zimmer J, Watson N, Treat A: Behavioral problems among patients in skilled nursing facilities. American Journal of Public Health. 1984; 74 (10): 1118-21.

3. Burgio L, Jones L, Butler F, Engle: Behavior problems in an urban nursing home. Journal of Gerontological Nursing. 1988; 14 (1): 31-34. 
4. National Center for Health Statistics (1989). The national nursing home survey, Series 13, \#97. Hyattsville, MD: DDHS, USPHS, \# 891758.

5. National Citizens Coalition for Nursing Home Reform (1989). Untie the elderly: Symposium co-sponsored by the US Senate Special Committee on Aging \& Kendall Corp. Silver Spring, MD: Manor Healthcare Corp.

6. Helms P: Efficacy of antipsychotics in the treatment of the behavioral complications of dementia. Journal of the American Geriatrics Society. 1985; 137: 1163-72.

7. Stumpf N, Evans L: Physical restraint of the hospitalized elderly. Nursing Research. 1988; 37 (3): 132-37.

8. US Congress (1987). Nursing Home Reform Act. Subtitle C, Omnibus Act, Public Law 100-203.

9. Kaplan R, Kaplan S: The experience of nature: A psychological perspective. Cambridge: Cambridge University Press, 1989.

10. Kaplan S, Kaplan R: Humanscape: Environments for people. Ann Arbor, MI: Ulrichs, 1982.
11. Randolph $\mathrm{C}$, Tierney $\mathrm{M}$, Chase $\mathrm{T}$ : Implicit memory in Alzheimer's disease. Journal of Clinical and Experimental Neuropsychology. 1995; 17(3): 343-51.

12. Sloane P, Rader J, Barrick A, Hoeffer B, Dwyer S, McKenzie D, Lavelle M, Buckwalter K, Arrington L, Pruitt T: Bathing persons with dementia. The Gerontologist. 1995; 35 (5): 672-678.

13. Cohen-Mansfield J, Marx MS, Rosenthal AS: A description of agitation in a nursing home. Journal of Gerontology. 1989; 44(3): M77-84.

14. Cohen-Mansfield J, Billig N: Agitated behaviors in the elderly. Journal of the American Geriatrics Society. 1986; 34: 711-721.

15. Chrisman M, Tabar D, Whall A, Booth D: Agitated behavior in cognitively impaired elderly. Journal of Gerontological Nursing. 1991; 17(12): 9-13.

16. Ryden M: Aggressive behavior in persons with dementia who live in the community. Alzheimer's Disease and Related Disorders. 1988; 2(4): 342-355.

\title{
Call for letters
}

Letters to the Editor will be considered for publication on matters of content and length.

Letters regarding articles published in American Journal of Alzheimer's Disease or related matters are welcome.

For best consideration, letters pertaining to a specific issue should be received as soon after publication as possible. All letters should be typewritten and double-spaced; references should be limited to five when possible.

Please include your full name, position, and address. Mail correspondence to the following address:

\author{
Letters to the Editor \\ American Journal of Alzheimer's Disease \\ 470 Boston Post Road \\ Weston, MA 02193 \\ Fax: 781-899-4900 \\ E-mail:alzheimers@pnpco.com \\ Website: www.alzheimersjournal.com
}

